\title{
What is the Prostate Specific Antigen Cut-off Value to Detect Metastases in Ga-68 Prostate Specific Membrane Antigen Ligand Positron Emission Tomography/ Computer Tomography Imaging for Intermediate and High-risk Prostate Cancer?
}

\author{
(D) Burak Köprü ${ }^{1}$, (1) Turgay Ebiloğlu², (1) Engin Kaya², (1) Engin Alagöz³ , (1) Murat Zor², (1) Mustafa Özdeş Emer³, \\ (D) Mesut Gürdal2, (1) Selahattin Bedir², (1) Nuri Arslan³ \\ ${ }^{1}$ Koru Ankara Hospital, Clinic of Urology, Ankara, Turkey \\ 2 Gülhane Training and Research Hospital, Clinic of Urology, Ankara, Turkey \\ 3 Gülhane Training and Research Hospital, Clinic of Nuclear Medicine, Ankara, Turkey
}

\begin{abstract}
Objective: The aim of this study was to detect a prostate specific antigen (PSA) cut-off value for metastases, and prevent unnecessary use of Ga-68 prostate specific membrane antigen (PSMA) ligand positron emission tomography/computer tomography (CT) imaging.

Materials and Methods: Between January 2016 and October 2017, patients with prostate cancer (PCa) who were staged using Ga-68 PSMA enrolled in this retrospective study.

Patients were divided into two groups: group 1 (G1) had Ga-68 PSMA for primary staging, and group 2 (G2) had Ga-68 PSMA for detection of metastases after treatment (secondary staging). PSA cut-off values were calculated for general, bone, lymph node and visceral metastases.

Results: A total of 181 patients were included in this study. PSA cut-off was $7.5 \mathrm{ng} / \mathrm{mL}$ for overall metastases in general. The PSA cut-offs for overall metastases using initial PSA were $8.98 \mathrm{ng} / \mathrm{mL}$ and $6.82 \mathrm{ng} / \mathrm{mL}$ for $\mathrm{G} 1$ and $\mathrm{G} 2$, respectively. For $\mathrm{G} 2$ patients the post-treatment PSA cut-off was $0.38 \mathrm{ng} / \mathrm{mL}$. For bone metastases, the PSA cut-offs using initial PSA were $8.98 \mathrm{ng} / \mathrm{mL}$ and $10.7 \mathrm{ng} / \mathrm{mL}$ for G1 and G2, respectively. For lymph node metastases, the PSA cut-offs using initial PSA were $8.98 \mathrm{ng} / \mathrm{mL}$ and $6.71 \mathrm{ng} / \mathrm{mL}$ for G1 and G2, respectively. For visceral metastases, the PSA cut-offs using initial PSA were $16.4 \mathrm{ng} / \mathrm{mL}$ and $7.08 \mathrm{ng} /$ $\mathrm{mL}$ for $\mathrm{G} 1$ and $\mathrm{G} 2$, respectively. The same analyses could not be calculated in subgroups of $\mathrm{G} 2$ due to small sample size.

Conclusion: These cut-off values do not suggest that Ga-68 PSMA is superior to using both CT and bone scintigraphy. It is an expensive test and its use is only reasonable when small lymph node metastases cannot be evaluated in CT.

Keywords: PSA, prostate cancer, Ga-68 PSMA ligand PET/CT
\end{abstract}

\section{Introduction}

Prostate cancer (PCa) is the most detected cancer and the second most common cause of cancer death among men in USA (1). The detection of PCa increased after the first reported use of prostate specific antigen (PSA) by Catalona et al. (2) in 1991, and the verification of PSA for cancer detection by the Food and Drug Administration in 1994 (3). PCa represents a broad-spectrum illness ranging from slow to aggressive disease (1). The major aim of PCa treatment is to convert the disease to an indolent form, as much as the treatment regimen allows. To select the most appropriate treatment modality, patients are categorised as low, intermediate and high-risk for PSA recurrence using the clinical stage, Gleason score and serum PSA level (4). Current the European Association of Urology guidelines suggest imaging with contrast-enhanced computerized tomography (CT) and bone scan (BS) for intermediate and high-risk patients to detect possible metastases. In addition, for high-risk patients, multiparametric magnetic resonance imaging of prostate (MPMRI-P) is also recommended for detection of local enlargement 
(4). However, CT is not a disease-specific imaging technique, and $B S$ is mostly suitable when the patient has bone pain and a serum PSA level of $>10 \mathrm{ng} / \mathrm{mL}$ (5).

Prostate specific membrane antigen (PSMA) is a type 2 transmembrane glycoprotein found in normal prostatic epithelium and overexpressed when PCa develops in normal prostatic tissue (6). Ga-68 PSMA ligand positron emission tomography (PET)/CT imaging is the name of radiotracer labelled with the Ga-68 radionuclide substance. It is endocytosed and collected beyond the cell membrane of $\mathrm{PCa}$ (7). It is an emerging imaging technique that could combine the advantages of CT and BS. After the initial diagnosis, Ga-68 PSMA can be used for both primary and secondary staging. For primary staging, conventional imaging techniques may not detect metastases: CT could omit some lymph nodes (5), and BS could omit bone metastases when PSA is $<10 \mathrm{ng} / \mathrm{mL}(7,8)$. These factors may play a role in choosing the treatment modality. For secondary staging, conventional techniques could fail to detect metastases unless the biochemical PSA recurrence reaches high levels (9).

In this study, our aim was to detect a PSA cut-off value for metastases and prevent unnecessary use of Ga-68 PSMA.

\section{Materials and Methods}

The ethical acceptance of this study was approved by the local Ethics Committee Private Koru Hospital and followed ethical standards described in the Helsinki Declaration (date: 05.01.2018).

Between January 2016 and October 2017, a total of 207 men with PCa who were staged using Ga-68 PSMA enrolled in this retrospective study (prospectively collected data reviewed retrospectively). The indications for Ga-68 PSMA were: PCa with the Gleason score $>6$, or any suspicion of metastases after any treatment for PCa.

For primary patients, the algorithm from elevated PSA level to application of a Ga-68 PSMA started from a transrectal ultrasound prostate biopsy when PSA was $\geq 4 \mathrm{ng} / \mathrm{mL}$, or abnormal palpation of prostate on rectal digital examination in patients with more than 10 years life expectancy. A minimum of a 12-core prostatic biopsy was taken with an 18 gauge Tru-cut biopsy needle.

For secondary patients who were treated for $\mathrm{PCa}$, the algorithm started with the suspicion of metastases in an imaging modality or with an elevated PSA level.

Patients with serum creatinine and bilirubin levels higher than two times of upper limit of normal, and patients with liver transaminase levels higher than three times of upper limit of normal were not directed to Ga-68 PSMA.

Twenty-six patients were excluded from the study due to excessive incomplete information. Patients were divided into two groups: group 1 (G1) had Ga-68 PSMA for primary staging, and group 2 (G2) had Ga-68 PSMA for detection of metastases after a treatment modality (secondary staging). Patients in G2 were divided into six groups: G2a had radical prostatectomy (RP), G2b had radiotherapy (RT) plus hormonotherapy (HT), G2c had HT alone, G2d had chemotherapy plus HT, G2e had RP plus RT, and G2f had RT plus chemotherapy.
The PSA value, pathology results, metastatic sites and maximum standard uptake value $\left(\right.$ SUV $_{\max }$ ) for metastatic sites were noted and compared. A PSA cut-off value was calculated for general, bone, lymph node and visceral metastases.

\section{Radiopharmaceutical and Imaging Protocols}

All PSMA PET/CT evaluations were performed at a single centre. Ga-68 PSMA-11 was prepared using a fully automated radiopharmaceutical synthesis device based on a modular concept (Eckert \& Ziegler Eurotope, Berlin, Germany). Briefly, a $\mathrm{TiO}_{2}$-based commercially available Ge-68/Ga-68 generator (Eckert \& Ziegler Eurotope) was eluted with $0.1 \mathrm{~N}$ hydrochloric acid and a $1.2 \mathrm{~mL}$ fraction was added to $5 \mathrm{nmol}$ of PSMA (ABX $\mathrm{GmbH}$, Radeberg, Germany); $\mathrm{pH}$ was adjusted to 3.5-4.0 by adding $1 \mathrm{~mol} / \mathrm{L}$ sodium acetate solution. The reaction was carried out at room temperature for $120 \mathrm{~s}$. The reaction solution was passed over a C18 cartridge (Sep-Pak; Waters Associates, Milford, Massachusetts, USA), washed with $5 \mathrm{~mL}$ of water, and finally eluted with $0.5 \mathrm{~mL} 95 \%$ ethanol, which was followed by saline through a $0.2 \mu \mathrm{m}$ sterile filter. Radiochemical purity, as determined by high performance liquid chromatography, exceeded $95 \%$ in all cases.

For image acquisition after the preparation and quality control of the radiotracer, all patients received 65 to $178 \mathrm{MBq}$ (mean 113.3 $\pm 21.2 \mathrm{MBq},<2 \mathrm{nmol}$ PSMA ligand) of Ga-68 PSMA11 according to the yield of the radiolabeling. Whole-body images acquired 45 to 60 minute post-injection of radiotracer using integrated PET/CT scanners: Discovery PET/CT 690 (GE Healthcare, Milwaukee, Wisconsin, USA). The patients were placed on the scanner table in a supine position and a CT transmission scan without intravenous contrast enhancement was acquired with a low tube current (130 kVp, 48-76 mAs), a slice thickness of $4.0 \mathrm{~mm}, 0.6 \mathrm{~s}$ gantry rotation, and a collimator width of $6 \times 3 \mathrm{~mm}$. Then, PET emission scanning with duration of 3 minute per bed position was performed with an identical transverse field of view in the caudocranial direction. For attenuation correction, CT transmission images were used and an iterative method was used for image reconstruction.

\section{Statistical Analysis}

Statistical analysis was done using Statistical Package for Social Sciences 20.0 Software (SPSS 20.0 for MAC). Descriptive statistics of nominal samples were expressed with numbers and percentiles. Descriptive statistics of scale samples were expressed as mean \pm standard deviation (minimum-maximum). Shapiro-Wilk, Kurtosis and Skewness tests were used to assess the variables' normalisation. The Mann-Whitney $U$ test was used to compare the pre and post procedure independent scale parameters without normal distribution. The Paired Sample t-test was used to compare the pre and post procedure dependent scale parameters with normal distribution. Pearson chi-square test was used to compare the independent nominal parameters. Pearson Correlation test was used to correlate two scale samples. Receiver operating characteristic (ROC) curve was used to detect a PSA cut-off. Probability of $p<0.05$ was accepted as statistically significant. 


\section{Results}

A total of 181 patients were included in this study. G1 and G2 included 71 and 110 patients, respectively. The mean patient age was 69.46 \pm 8.22 (range 53-86) years in G1 and 68.21 \pm 9.44 $(41-88)$ years in G2. The median PSA value was 15.0 (3-3000) $\mathrm{ng} / \mathrm{mL}$ in G1, and 18.21 (1.02-1260) ng/mL in G2 at the initial diagnosis of $\mathrm{PCa}$. After the treatment modalities, the median PSA value was $0.78(0.01-81) \mathrm{ng} / \mathrm{mL}$ in G2. The median PSA values were $0.24(0.01-0.53) \mathrm{ng} / \mathrm{mL}, 13.63(0.01-81) \mathrm{ng} / \mathrm{mL}$, $0.26(0.01-0.3) \mathrm{ng} / \mathrm{mL}, 3.84(0.24-13.8) \mathrm{ng} / \mathrm{mL}, 3.44(0.21-8)$ $\mathrm{ng} / \mathrm{mL}$, and 17.85 (0.01-69.2) ng/mL in G2a, G2b, G2c, G2d, G2e and G2f, respectively.

The pathologic results and pathologic Ga-68 PSMA uptake in detail for each site of body is expressed in Table 1. The most common metastatic regions were the lymph nodes and bone in G1 and G2, respectively. The most common metastatic bone sites were the sternum and costa, with $15(21.1 \%)$ and $41(37.3 \%)$ metastases, respectively $(p=0.002)$. The most common metastatic lymph node regions were the internal iliac, external iliac and obturator lymph nodes with 20 (28.2\%) and $30(27.3 \%)$ metastases, respectively $(p=0.895)$. The third metastatic region was the visceral organs, and the most common metastatic visceral organ was lung with $2(2.8 \%)$ and $12(10.9 \%)$ pathologic uptake in $\mathrm{G} 1$ and $\mathrm{G} 2$, respectively $(p=0.042)$ (Table 1).

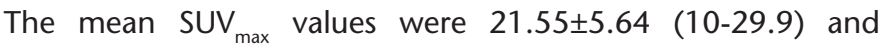
$25.4 \pm 18.9$ (2.4-74) for bone metastases ( $p=0938) ; 28.9 \pm 17.39$ (10.9-52) and 25.69 \pm 18.02 (7-59) for lymph node metastases $(p=0.902)$; and 19.1 $\pm 9.44(41-88)$ and $21.30 \pm 29.7$ (7-82) for visceral metastases $(p=0.571)$ in $G 1$ and $G 2$, respectively. There was a significant correlation between PSA and SUV max $_{\text {values }}$ for bone $(p=0.001)$ and lymph node $(p=0.015)$ metastases in G1 (Figure 1). There was a significant and non-significant correlation for bone $(p=0.004)$ and lymph node $(p=0.304)$ metastases in G2. The correlation could not be calculated for visceral metastases due to small sample size. For G1 patients, there was a linear correlation between PSA and SUV ${ }_{\max }$. For G2 patients, the linear correlation was only significant when the PSA was between $24-26$ and $14-25 \mathrm{ng} / \mathrm{mL}$.

The overall area under curve value of the ROC curve formed using PSA to detect any metastases in the body was 0.727 , and the PSA cut-off was $7.5 \mathrm{ng} / \mathrm{mL}$ with $80 \%$ sensitivity and $60 \%$ specificity. The area under curve values were 0.78 and 0.68 in G1 and G2, respectively (Figure 2). The PSA cut-offs for overall metastases using initial PSA were $8.98 \mathrm{ng} / \mathrm{mL}$ and $6.82 \mathrm{ng} / \mathrm{mL}$ with $80 \%$ sensitivity and $60 \%$ specificity for G1 and G2. For G2 patients the post-treatment PSA cut-off was $0.38 \mathrm{ng} / \mathrm{mL}$. For G2a, G2b, G2d, G2e and G2f, the post-treatment PSA cut-offs were $0.31 \mathrm{ng} / \mathrm{mL}, 0.95 \mathrm{ng} / \mathrm{mL} 0.27 \mathrm{ng} / \mathrm{mL}, 1.71 \mathrm{ng} / \mathrm{mL}$ and $0.05 \mathrm{ng} / \mathrm{mL}$, respectively. For G2c, a post-treatment PSA cut-off could not be detected due to sample size (Table 2).

For bone metastases, the PSA cut-offs using initial PSA were 8.98 $\mathrm{ng} / \mathrm{mL}$ and $10.7 \mathrm{ng} / \mathrm{mL}$ for $\mathrm{G} 1$ and $\mathrm{G} 2$, respectively. For lymph node metastases, the PSA cut-offs using initial PSA were 8.98 $\mathrm{ng} / \mathrm{mL}$ and $6.71 \mathrm{ng} / \mathrm{mL}$ for $\mathrm{G} 1$ and $\mathrm{G} 2$ at first diagnosis. For visceral metastases, the PSA cut-offs using initial PSA were 16.4 $\mathrm{ng} / \mathrm{mL}$ and $7.08 \mathrm{ng} / \mathrm{mL}$ for G1 and G2 at first diagnosis (Table
2). The same analyses could not be calculated in subgroups of G2 due to small sample size.

\section{Discussion}

New techniques and developments in the detection of clinically significant PCa to determine treatment modality have been the main topics of reports in the last decade. The most commonly used imaging techniques for staging $\mathrm{PC}$ a are $\mathrm{CT}, \mathrm{BS}$ and MP-

\begin{tabular}{|c|c|c|c|}
\hline & G1 (n, \%) & G2 (n, \%) & $\mathbf{p}^{*}$ \\
\hline Gleason $3+3$ & $4(7)$ & $2(4)$ & \multirow{8}{*}{0.009} \\
\hline Gleason $3+4$ & $4(7)$ & $3(6)$ & \\
\hline Gleason $4+3$ & $18(33)$ & $10(21)$ & \\
\hline Gleason 4+4 & $8(14)$ & $9(20)$ & \\
\hline Gleason $4+5$ & $11(20)$ & $30(23)$ & \\
\hline Gleason $5+3$ & $2(3)$ & $2(4)$ & \\
\hline Gleason $5+4$ & $1(1)$ & $4(8)$ & \\
\hline Gleason $5+5$ & $6(2)$ & $6(14)$ & \\
\hline Visceral metastasis & $4(5.6)$ & $16(14.5)$ & 0.062 \\
\hline Lymph node metastasis & $25(35.2)$ & $44(40)$ & 0.517 \\
\hline Parotis gland metastasis & 0 & $1(0.09)$ & 0.521 \\
\hline Submandibular gland metastasis & 0 & 0 & - \\
\hline Lacrimal gland metastases & 0 & $1(0.09)$ & 0.608 \\
\hline Tiroid metastasis & 0 & $3(2.7)$ & 0.222 \\
\hline $\begin{array}{l}\text { Supraclavicular lymph node } \\
\text { metastasis }\end{array}$ & $2(2.8)$ & $6(5.5)$ & 0.327 \\
\hline Lung metastasis & $2(2.8)$ & $12(10.9)$ & 0.042 \\
\hline Hiler lymph node metastasis & $10(14.1)$ & $18(16.4)$ & 0.424 \\
\hline Hepatic metastases & $2(2.8)$ & $6(5.5)$ & 0.327 \\
\hline Spleen metastasis & 0 & 0 & - \\
\hline Kidney metastases & 0 & 0 & - \\
\hline $\begin{array}{l}\text { Paraaortic + paracaval }+ \\
\text { aortocaval lymph node metastasis }\end{array}$ & $12(16.9)$ & $24(21.8)$ & 0.418 \\
\hline $\begin{array}{l}\text { Internal + external iliac }+ \\
\text { obturatuar lymph node metastasis }\end{array}$ & $20(28.2)$ & $30(27.3)$ & 0.895 \\
\hline Inguinal lymph node metastasis & $5(7)$ & $6(5.5)$ & 0.445 \\
\hline $\begin{array}{l}\text { Multiple abdominal lymph } \\
\text { nodes metastasis }\end{array}$ & $9(12.7)$ & $17(15.5)$ & 0.603 \\
\hline Pararectal metastasis & $12(6.9)$ & $10(9.1)$ & 0.119 \\
\hline Prostatic uptake & $56(78.9)$ & $32(29.1)$ & 0.001 \\
\hline Bone metastasis & $18(25.4)$ & $63(57.3)$ & 0.001 \\
\hline Multiple bone metastasis & $13(18.3)$ & $42(38.2)$ & 0.005 \\
\hline Cranial metastasis & $5(7)$ & $22(20)$ & 0.016 \\
\hline Vertebral metastasis & $13(18.3)$ & $51(46.4)$ & 0.001 \\
\hline Sternal and costa metastasis & $15(21.1)$ & $41(37.3)$ & 0.02 \\
\hline Acatabular metastasis & $11(15.5)$ & $40(36.4)$ & 0.02 \\
\hline Pubis metastasis & $14(19.7)$ & $38(34.5)$ & 0.031 \\
\hline Sacral metastasis & $11(15.5)$ & $36(32.7)$ & 0.009 \\
\hline \multicolumn{4}{|c|}{ G1: Group 1, G2: Group 2, *Pearson chi square test } \\
\hline
\end{tabular}




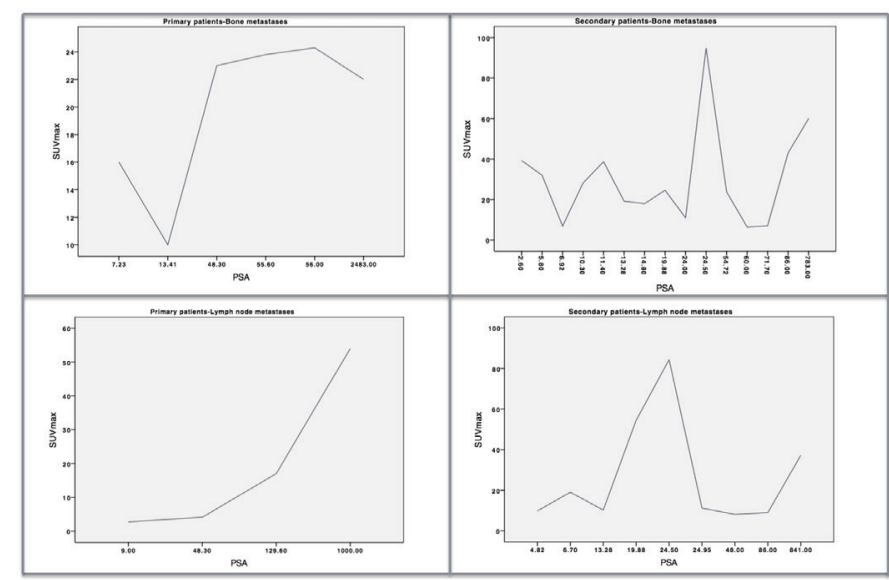

Figure 1. The correlation between PSA and SUV ${ }_{\text {max }}$

PSA: Prostate specific antigen, SUV: Standardized uptake value
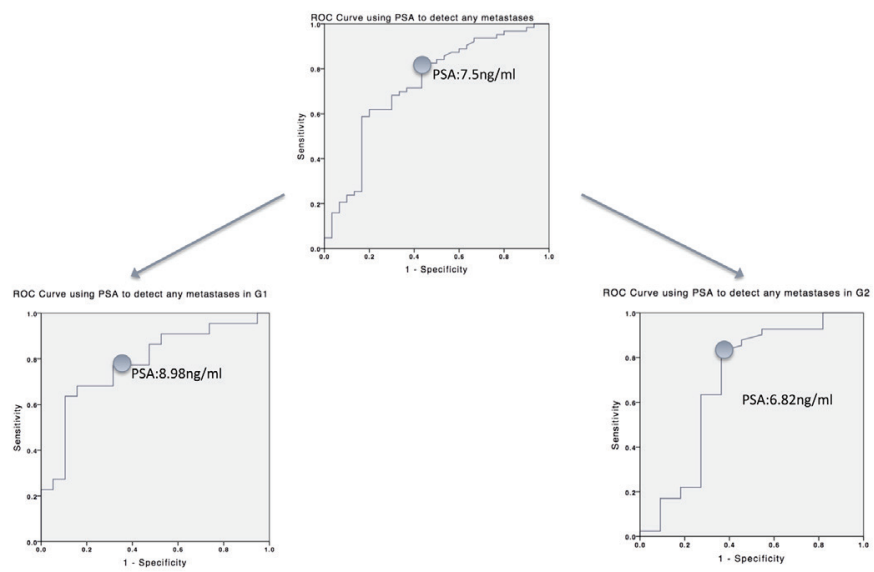

Figure 2. The PSA cut-off using initial PSA for primary and secondary patients PSA: Prostate specific antigen, ROC: Receiver operating characteristic, G1: Group 1, G2: Group 2

MRI-P. However, they have some limitations. CT has reported to have lack in T staging due to low contrast uptake in soft tissue, and lack in $\mathrm{N}$ staging due to not detecting small lymph nodes. Eighty percent of lymph node metastases in PCa are reported to be $<8 \mathrm{~mm}$ (10). BS is used to examine the skeletal metastases, but it has a low specificity and low detection rates when PSA is $<7 \mathrm{ng} / \mathrm{mL}$ (8). MP-MRI-P is considered the best imaging technique to evaluate close structures surrounding the prostate (11). However, in a series of 40 prostate lesions, 32 lesions had significant uptake outside the lesion detected in MP-MRI-P (12).

An imaging technique detecting skeletal, lymph node and visceral metastases in a single setting, also evaluating the prostatic lesions and neighbourhood of prostate would be reasonable for PCa staging. For this reason, Ga-68 PMSA is a significant step for patients with Gleason score occurrence of biochemically PSA recurrence. However, Meyrick et al. (6) examined the Ga-68 PSMA for primary staging and reported a $34 \%$ detection rate of metastatic disease. They also reported a $50 \%$ rate of nodal metastases, and a $17 \%$ rate of skeletal metastases in these patients, but they did not explain the metastatic disease well
Table 2. The detailed prostate specific antigen cut-off values for primary and secondary patients

\begin{tabular}{|c|c|c|c|}
\hline Metastases & $\begin{array}{l}\text { Initial } \\
\text { PSA cut-off } \\
(\mathrm{ng} / \mathrm{mL})\end{array}$ & $\begin{array}{l}\text { Sensitivity } \\
(\%)\end{array}$ & $\begin{array}{l}\text { Specificity } \\
\text { (\%) }\end{array}$ \\
\hline Any site for overall & 7.5 & 80 & 60 \\
\hline Metastases & $\begin{array}{l}\text { Initial } \\
\text { PSA cut-off } \\
(\mathrm{ng} / \mathrm{mL})\end{array}$ & $\begin{array}{l}\text { Sensitivity } \\
(\%)\end{array}$ & $\begin{array}{l}\text { Specificity } \\
(\%)\end{array}$ \\
\hline Any site for G1 & 8.98 & 80 & 60 \\
\hline Bone for G1 & 8.98 & 80 & 40 \\
\hline Lymph node for G1 & 9.98 & 80 & 60 \\
\hline Visceral for G1 & 16.4 & 100 & 40 \\
\hline Metastases & $\begin{array}{l}\text { Initial } \\
\text { PSA cut-off } \\
(\mathrm{ng} / \mathrm{mL})\end{array}$ & $\begin{array}{l}\text { Sensitivity } \\
(\%)\end{array}$ & $\begin{array}{l}\text { Specificity } \\
(\%)\end{array}$ \\
\hline Any site for G2 & 6.82 & 80 & 60 \\
\hline Bone for G2 & 10.7 & 80 & 60 \\
\hline Lymph node for G2 & 6.71 & 80 & 40 \\
\hline Visceral for G2 & 7.08 & 80 & 40 \\
\hline Metastases & $\begin{array}{l}\text { Post-treatment } \\
\text { PSA cut-off } \\
\text { (ng/mL) }\end{array}$ & $\begin{array}{l}\text { Sensitivity } \\
(\%)\end{array}$ & $\begin{array}{l}\text { Specificity } \\
(\%)\end{array}$ \\
\hline Any site for G2 & 0.38 & 81 & 79 \\
\hline Bone for G2 & 0.27 & 84 & 55 \\
\hline Lymph node for G2 & 0.38 & 80 & 50 \\
\hline Visceral for G2 & 0.38 & 70 & 48 \\
\hline \multicolumn{4}{|l|}{ Subgroups of G2 } \\
\hline Metastases & $\begin{array}{l}\text { Post-treatment } \\
\text { PSA cut-off } \\
(\mathrm{ng} / \mathrm{mL})\end{array}$ & $\begin{array}{l}\text { Sensitivity } \\
(\%)\end{array}$ & $\begin{array}{l}\text { Specificity } \\
(\%)\end{array}$ \\
\hline Any site for $\mathrm{G} 2 \mathrm{a}$ & 0.31 & 100 & 100 \\
\hline Any site for $\mathrm{G} 2 \mathrm{~b}$ & 0.95 & 75 & 75 \\
\hline Any site for $G 2 c$ & - & - & - \\
\hline Any site for G2d & 0.27 & 70 & 100 \\
\hline Any site for G2e & 1.71 & 100 & 100 \\
\hline Any site for G2f & 0.05 & 100 & 45 \\
\hline
\end{tabular}

in material methods section and did not examine the skeletal and nodal metastases in a setting separate from metastatic disease. In our study, we detected $5.6 \%, 35.2 \%$ and $25.4 \%$ of visceral, nodal and bone metastases, respectively, in primary staging. Our detection rate is similar to that of Meyrick et al. (6) if we describe metastatic disease as the combination of visceral, nodal and skeletal metastases. According to Gleason score, our patients had less aggressive disease than those of Meyrick et al. (6). They reported 31\%, 28\% and 32\% patients with Gleason score $<7,<8$ and $>9$, respectively ( $9 \%$ missing). In our series, the same parameters were $47 \%, 14 \%$ and $26 \%$ (13\% missing). The same study revealed that patients with higher PSA values have more metastases in Ga-68 PSMA after categorising the PSA as $0-5 \mathrm{ng} / \mathrm{mL}, 5-10 \mathrm{ng} / \mathrm{mL}$ and $>10 \mathrm{ng} / \mathrm{mL}$. However, they could not provide a $\mathrm{p}$ value due to inability to correlate a scale sample with a nominal sample. Our results are compatible with 
the mentioned study. Differently from the mentioned study, we correlated the PSA and SUV max' and in our findings, the linear

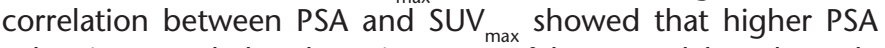
value increased the detection rate of bone and lymph node metastases in primary staging of PCa. The other studies of Ga68 PSMA and primary staging have insufficient patient size or are inappropriate to compare to our study (7).

For secondary staging, Mena et al. (12) reported $60 \%$ overall recurrence using F18-PSMA in patients with detected PSA recurrence after primary local therapy. The locations of the progressions were prostate bed, lymph nodes and distant sites (12). Sanli et al. (13) reported 51 local recurrence, $42 \%$ lymph node metastases, and $50 \%$ bone metastases in their series of 109 patients with PSA recurrence. Afshar-Oromieh et al. (14) reported $86.5 \%$ organ recurrence; Eiber et al. (15) reported a $58 \%$ metastasis detection rate for PSA levels below $0.5 \mathrm{ng} /$ $\mathrm{mL}$, and a $73 \%$ detection rate for PSA levels below $10 \mathrm{ng} / \mathrm{mL}$; Budaus et al. (16) reported 33\% sensitivity and 100\% specificity for detection of lymph node metastases using Ga-68 PSMA. In our series, there were $68.2 \%, 14.5 \%, 40 \%$ and $57.3 \%$ overall, visceral, nodal and bone metastases in secondary staging, respectively. Our results are similar to the literature. However, due to the heterogeneous structure of studies above, it is difficult to make an exact comparison. The median reported Gleason score was 7 in the studies about secondary staging $(13,14,17)$. According to Gleason score, our patients seem to have more aggressive disease than the studies in literature. In our study, most of our patients had Gleason score 9 PCa. The studies examining PSA and Ga-68 PSMA uptake for secondary staging reported that a higher PSA recurrence value led to detection of more metastases with Ga-68 PSMA $(13,15)$. However, they could not make an exact correlation. We correlated the PSA and SUV $_{\text {max }}{ }^{\prime}$ and the significant correlation between PSA and SUV for oligometastases in secondary staging. The same outcome could not be concluded for lymph node and visceral metastases.

The primary goal of our study was to determine PSA cut-off values for Ga-68 PSMA. To our knowledge, no one reported a PSA cut-off in Ga-68 PSMA for primary staging of PCa. In our study, we detected $8.98 \mathrm{ng} / \mathrm{mL}$ as a cut-off for overall metastases in primary staging. Examining in detail, $8.98 \mathrm{ng} / \mathrm{mL}$ was a cutoff for bone and lymph node metastases. However, for visceral metastases it was detected to be $16.4 \mathrm{ng} / \mathrm{mL}$. For secondary staging, there are many reports trying to find out a PSA cut-off. Mena et al. (12) reported $0.78 \mathrm{ng} / \mathrm{mL}$ as a cut-off for overall detection of metastases; Sanli et al. (13) reported $0.67 \mathrm{ng} /$ $\mathrm{mL}, 1.23 \mathrm{ng} / \mathrm{mL}, 0.68 \mathrm{ng} / \mathrm{mL}$ and $2.35 \mathrm{ng} / \mathrm{mL}$ as cut-offs for overall, local recurrence, lymph node and bone metastases, respectively; Ceci et al. (17) reported $0.83 \mathrm{ng} / \mathrm{mL}$ as a cut-off for overall metastases in secondary staging. The differences between our study and the above-mentioned studies are the evaluation of the initial PSA value to create a cut-off, and the classification of patients according to their treatment regimens. We thought that the initial PSA value could be an indicator for evaluating the patients after a treatment modality, and that different regimens could cause different PSA decrease in followup. We detected $6.82 \mathrm{ng} / \mathrm{mL}, 10.7 \mathrm{ng} / \mathrm{mL}, 6.71 \mathrm{ng} / \mathrm{mL}$ and $7.08 \mathrm{ng} / \mathrm{mL}$ as cut-offs using initial PSA for overall, bone, lymph node and visceral metastases in secondary staging, respectively.
We also detected $0.38 \mathrm{ng} / \mathrm{mL}$ as a cut-off using post-treatment PSA for overall metastases. Our post-treatment PSA cut-off value seems lower than the studies above. In subgroups of secondary staging, the post-treatment PSA cut-offs were $0.31 \mathrm{ng} / \mathrm{mL}, 0.95$ $\mathrm{ng} / \mathrm{mL}, 0.27 \mathrm{ng} / \mathrm{mL}, 1.71 \mathrm{ng} / \mathrm{mL}$ and $0.05 \mathrm{ng} / \mathrm{mL}$ for overall metastases in G2a, G2b, G2d, G2e and G2f, respectively. For G2c, a post-treatment PSA cut-off could not be detected due to sample size. In addition, we also could not calculate the cutoff values using post-treatment PSA for bone, lymph node and visceral metastases separately in subgroups of secondary staging due to small sample size.

Over all of these conditions, the cost-effectiveness is a major problem. Using both CT and BS for staging is extremely cheaper than Ga-68 PSMA alone, and the PSA cut-off values we detected do not make it superior than BS for bone metastases. We think that its use is only reasonable when small lymph node metastases cannot be evaluated in BT.

\section{Study Limitations}

There are many limitations of our study. Firstly, our series consists of heterogeneous subgroups. Studies examining the subgroups with more patients will reveal better results than ours. Secondly, the detected metastases in our series were not proven using histological or radiographic methods. However, it was impractical and unethical to guide every patient to biopsy for staging of $\mathrm{PCa}$, and using conventional imaging sectioning concomitantly with Ga-68 PSMA would not be cost-effective.

\section{Conclusion}

The PSA cut-off for overall metastases was detected as $8.98 \mathrm{ng} /$ $\mathrm{mL}$ for primary staging. The PSA cut-off using initial PSA for overall metastases was detected as $6.82 \mathrm{ng} / \mathrm{mL}$ for secondary staging. The PSA cut-off using post-treatment PSA for overall metastases was detected as $0.38 \mathrm{ng} / \mathrm{mL}$ for secondary staging.

These cut-off values do not make it extremely superior than using both CT and BS and it is an expensive test. We think that its use is only reasonable when small lymph node metastases cannot be evaluated in CT.

\section{Acknowledgements}

Publication: The results of the study were not published in full or in part in form of abstracts.

Contribution: There is not any contributors who may not be listed as authors.

Conflict of Interest: No conflict of interest was declared by the authors.

Financial Disclosure: The authors declared that this study received no financial support.

\section{Ethics}

Ethics Committee Approval: The ethical acceptance of this study was approved by the local Ethics Committee Private Koru Hospital and followed ethical standards described in the Helsinki Declaration (date: 05.01.2018).

Informed Consent: Retrospective study. 
Peer-review: Externally peer-reviewed.

\section{Authorship Contributions}

Supervision: M.G., N.A., Critical Review: M.G., N.A., Concept B.K., T.E., Design: B.K., T.E., Data Collection or Processing: E.K., E.A., Analysis or Interpretation: M.Z., M.Ö.E., Literature Search: S.B., Writing: B.K., T.E., E.K.

\section{References}

1. American Cancer Society: Cancer Facts and Figures 2016:4-5.

2. Catalona WJ, Smith DS, Ratliff TL, et al. Measurement of prostatespecific antigen in serum as a screening test for prostate cancer. $\mathrm{N}$ Engl J Med 1991;324:1156-1161.

3. Nogueira L, Corradi R, Eastham JA. Prostatic specific antigen for prostate cancer detection. Int Braz J Urol 2009;35:521-529.

4. Mottet N, Bastian PJ, Bellmunt J, et al. Guidelines on Prostate Cancer. In: European Association of Urology 2016:15-22.

5. Abuzallouf S, Dayes I, Lukka H. Baseline staging of newly diagnosed prostate cancer: a summary of the literature. J Urol 2004; 171:2122-2127.

6. Meyrick DP, Asokendaran M, Skelly LA, et al. The role of 68Ga-PSMAI\&T PET/CT in the pretreatment staging of primary prostate cancer. Nucl Med Commun 2017;38:956-963.

7. Bailey J, Piert M. Performance of 68Ga-PSMA PET/CT for Prostate Cancer Management at Initial Staging and Time of Biochemical Recurrence. Curr Urol Rep 2017; 19:84.

8. Jambor I, Kuisma A, Ramadan S, et al. Prospective evaluation of planar bone scintigraphy, SPECT, SPECT/CT, 18F-NaF PET/CT and whole body 1.5T MRI, including DWI, for the detection of bone metastases in high risk breast and prostate cancer patients: SKELETA clinical trial. Acta Oncol 2016;55:59-67.
9. Freedland SJ, Humphreys EB, Mangold LA, et al. Risk of prostate cancer-specific mortality following biochemical recurrence after radical prostatectomy. JAMA 2005;294:433-439.

10. Maurer T, Gschwend J.E, Rauscher I, et al. Diagnostic Efficacy of (68) Gallium-PSMA Positron Emission Tomography Compared to Conventional Imaging for Lymph Node Staging of 130 Consecutive Patients with Intermediate to High Risk Prostate Cancer. J Urol 2016; 195:1436-1443.

11. Thompson JE, Van Leeuwen PJ, Moses D, et al. The Diagnostic Performance of Multiparametric Magnetic Resonance Imaging to Detect Significant Prostate Cancer. J Urol 2016;195:1428-1435.

12. Mena $E$, Lindenberg $M L$, Shih JH, et al. Clinical impact of PSMAbased 18F-DCFBC PET/CT imaging in patients with biochemically recurrent prostate cancer after primary local therapy. Eur J Nucl Med Mol Imaging 2018;45:4-11.

13. Sanli Y, Kuyumcu S, Sanli O, et al. Relationships between serum PSA levels, Gleason scores and results of 68Ga-PSMAPET/CT in patients with recurrent prostate cancer. Ann Nucl Med 2017;31:709-717.

14. Afshar-Oromieh A, Zechmann CM, Malcher A, et al. Comparison of PET imaging with a (68) Ga-labelled PSMA ligand and (18) F-cholinebased PET/CT for the diagnosis of recurrent prostate cancer. Eur J Nucl Med Mol Imaging 2014;41:11-20.

15. Eiber M, Maurer T, Souvatzoglou M, et al. Evaluation of Hybrid (6)(8) Ga-PSMA Ligand PET/CT in 248 Patients with Biochemical Recurrence After Radical Prostatectomy. J Nucl Med 2015;56:668-674.

16. Budaus L, Leyh-Bannurah SR, Salomon G, et al. Initial Experience of (68) Ga-PSMA PET/CT Imaging in High-risk Prostate Cancer Patients Prior to Radical Prostatectomy. Eur Urol 2016;69:393-396.

17. Ceci F, Uprimny C, Nilica B, et al. (68) Ga-PSMA PET/CT for restaging recurrent prostate cancer: which factors are associated with PET/CT detection rate? Eur J Nucl Med Mol Imaging 2015;42:1284-1294. 